\title{
Interactive comment on "Effects of coupled hydro-mechanical model considering two-phase fluid flow on potential for shallow landslides: a case study in Halmidang Mountain, Yongin, South Korea” by Sinhang Kang and Byungmin Kim
}

Anonymous Referee \#2

Received and published: 18 April 2020

\section{General comments}

After reading the discussion version, the first referee's comment and author's reply to that comment of this article, I post this comment to this article. I totally agree to the first referee's comment with eight questions which are truly considerable.

The research focusing on the regional shallow landslide susceptibility emphasizes on the mechanism based on the coupled hydro-mechanical model. The novelty in this paper is to consider two-phase fluid flow of water and air in the regional area, aiming

Printer-friendly version

Discussion paper 
at obtaining the changes in pore and water pressures and saturations of air and water. However, the research lacks the detailed information and the full evidences explaining the reason why the coupled hydro-mechanical model is better the single-phase flow model.

\section{Specific comments}

Applying the physical mechanical is not easy, more information should be added, and the research work should be described.

1. In line 7, compared to the detailed information in section of study area, "More than 30 shallow landslides" is not clear. Please revise it.

2. The accuracy comparison. In line 17, your result with coupled hydro-mechanical model is "slightly" more consistent with the single-phase flow model. Although your presentation in the whole paper is good, the result is just slightly better. Also in Line 314 and line 317 , the accuracy comparison of 0.89 vs 0.86 and $90.7 \%$ vs $91 \%$. What is the meaning of your research?

3. In line 65, the paper mentioned the outcropping lithology. This area only includes two kinds of lithology, or this two lithology are the main types? Detailed lithology information should be described, better with a map, if necessary.

4. In line 71, 36 shallow landslide occurred at Halmidang Mountain. In line 73, debris flow occurred along 21 watersheds. In line 89 landslide inventories comprise information. In line 90, you applied performance evaluation. In line 93, you checked the accuracy of the landslide inventories. Please add the landslide inventory in this manuscript. What are types of these 36 natural hazard? As I cannot understand the meaning of landslide in your manuscript. The landslide means the natural hazards in the broad concept, or specific debris flow. Also please simply describe the work of performance evaluation. Please describe the accuracy of the landslide inventories.

5. In line 200-206, I cannot understand how to make the figure6 and figure7? To be

Printer-friendly version

Discussion paper 
specific, in the zone 1 of figure 6 , there are eleven points in the time line of $0 \mathrm{~h}$. Could you please describe it?

6. In the line 204 , why you set the infinite slope $30^{\circ}$ ? The case study is a regional area. Are the conditions in the 12 zones the same?

7. In section 5.3.1, you aim to compare the coupled hydro-mechanical and single phase flow model. Please do not neglect the parameter sensitivity. For example, in figure 6 , the plot of line and point are very similar in zone 1 , zone 3 and zone 8 . I see the parameters in Table 2, the parameters are not similar. Please explain.

8. What is the criterion of the division of 12 zones? As you divide the whole area into 12 zones, then the number of zone should be added into the Table I.

9. In the figure 2, the landslide occurs at 14:00. All or several the landslides happened at that time? Please support detailed information.

\section{Technical corrections}

1. Table I, please check the unit and the value of $\gamma \mathrm{t}$ and $\gamma \mathrm{d}$. The detailed information of all samples should be added.

2. Table II, please define the $\alpha, \mathrm{n}$ and $\mathrm{m}$.

3. Please zoom in two panels in Figure 5.

Interactive comment on Nat. Hazards Earth Syst. Sci. Discuss., https://doi.org/10.5194/nhess2019-271, 2019. 